\title{
Anatomical and histological analysis of the salpinx and ovary in Anatolian wild goat (Capra aegagrus aegagrus)
}

\author{
G. Kırbaş Doğan', M. Kuru², B. Bakır³, E. Karadağ Sarı \\ ${ }^{1}$ Department of Anatomy, Faculty of Veterinary Medicine, University of Kafkas, Kars, Turkey \\ ${ }^{2}$ Department of Obstetrics and Gynaecology, Faculty of Veterinary Medicine, University of Kafkas, Kars, Turkey \\ ${ }^{3}$ Department of Histology and Embryology, Faculty of Veterinary Medicine, University of Namık Kemal, Tekirdağ, Turkey \\ ${ }^{4}$ Department of Histology and Embryology, Faculty of Veterinary Medicine, University of Kafkas, Kars, Turkey
}

[Received: 2 January 2019; Accepted: 26 February 2019]

\begin{abstract}
Background: This study determined the anatomical and histological structure of the salpinx and ovary of the Anatolian wild goat (C. aegagrus aegagrus).

Materials and methods: The salpinges and ovaries from four wild goats of similar ages were used. These goats were brought to the Kafkas University Wildlife Rescue and Rehabilitation Centre (Kars, Turkey) for various reasons such as traffic accidents or firearm injury, but either could not be saved or were euthanased. Results: The mean length of the ovary was $13.22 \pm 1.27 \mathrm{~mm}$, width was $8.46 \pm$ $\pm 0.88 \mathrm{~mm}$, thickness was $5.67 \pm 0.79 \mathrm{~mm}$, and weight was $0.59 \pm 0.17 \mathrm{~g}$. The mean length of the salpinx was $58.11 \pm 14.02 \mathrm{~mm}$, width was $0.80 \pm 0.22 \mathrm{~mm}$, thickness was $0.41 \pm 0.01 \mathrm{~mm}$, and weight was $0.30 \pm 0.08 \mathrm{~g}$. The salpinx consisted of three different regions (infundibulum, ampulla, and isthmus). These regions consisted of tunica mucosa, tunica muscularis, and tunica serosa. Prismatic epithelial cells were observed in the lamina epithelialis of the tunica mucosa in every region. Conclusions: The data resulting from this study regarding anatomical and histological structures of the salpinx and ovary in the genital system organs of Anatolian wild goat will support other studies seeking to improve reproductive efficiency and eliminate the danger of extinction of this species. (Folia Morphol 2019; 78; 4: 827-832)
\end{abstract}

Key words: Anatolian wild goat, anatomy, ovary, salpinx

\section{INTRODUCTION}

The Anatolian wild goat (Capra aegagrus hircus) is a subspecies of Capra (chamois), which has nine species. The domestic goat (C. aegagrus hircus) is a domesticated subspecies of the wild goat [2]. Wild goat, which lives in some countries of the Caucasus and Middle East, is found in the Aegean, Mediterranean, South-eastern Anatolia, Eastern Anatolia, and Black Sea regions 4000-4500 m above sea level (Fig. 1) [3].

The ovaries are two organs in the right and left pelvic canal. They are round-oval or almond shaped in sheep and goats. Ovaries have both endocrine and exocrine functions. The weight is $1.8-3.5 \mathrm{~g}$ and length is 10$-20 \mathrm{~mm}[1,17]$. The ovary is divided into two functional parts, the cortex and medulla. Because the cortex is a functional section, it is called the zona parenchymatosa. The medulla, which is rich in blood and lymphatic vessels, is also called the zona vasculosa [1]. The salpinx delivers the ovum to the uterus and the spermatozoa to the ovum. It also connects the ovary and uterus. It consists of three sections (infundibulum, ampulla, and isthmus) with an average length of 100-160 mm [17].

Address for correspondence: Dr. G. Kırbaş Doğan, The University of Kafkas, Faculty of Veterinary Medicine, Department of Anatomy, Kars, Turkey, tel: 05398566871, e-mail: glsrn36@gmail.com

This study's abstract was presented in oral "ICVBS 2018: $20^{\text {th }}$ International Conference on Veterinary and Biomedical Sciences". 


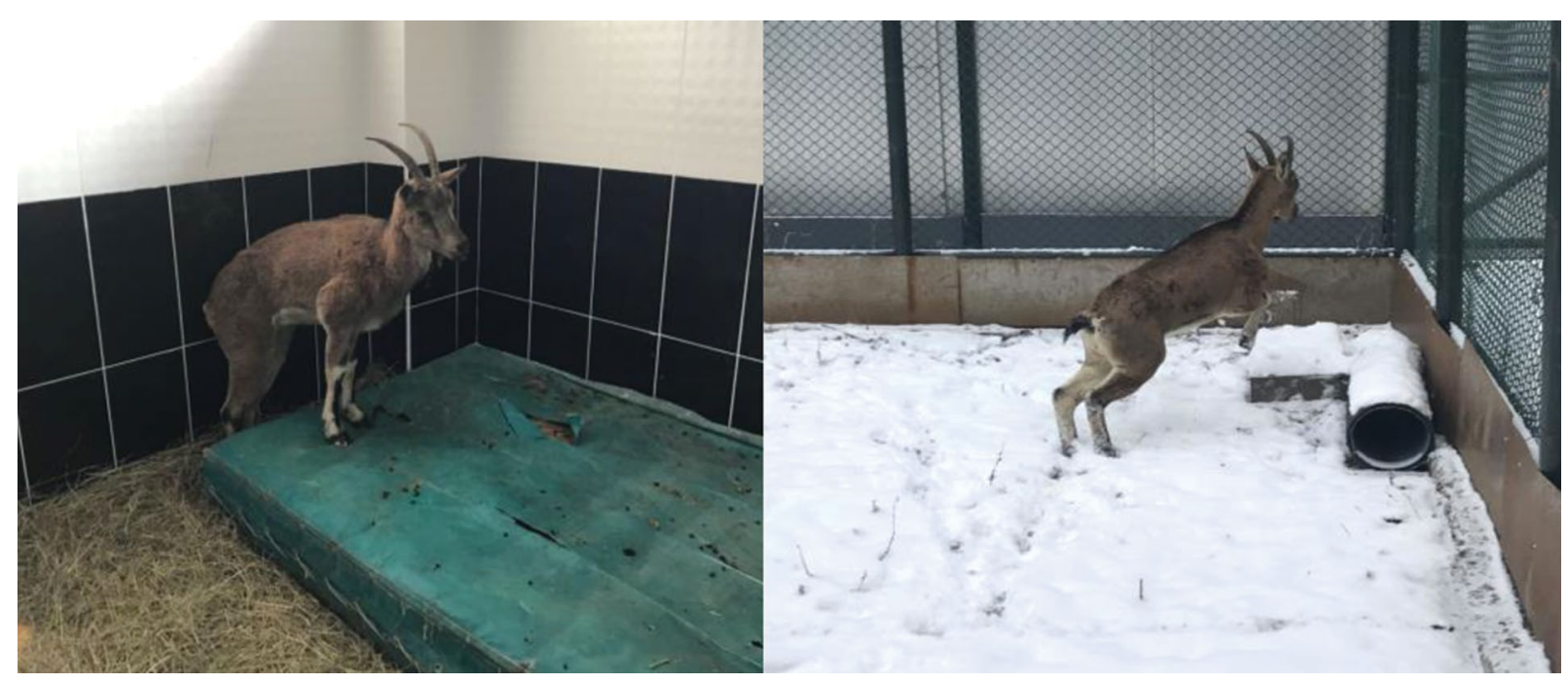

Figure 1. Anatolian wild goat (Capra aegagrus hircus) in Kafkas University Wildlife Rescue and Rehabilitation Centre (Kars, Turkey).

The salpinx is an important organ in mammalian reproduction $[7,11]$. The epithelium of the oviduct plays a significant role in the secretion of oviductal fluids, vital for the survival and transportation of gametes, and provides an intrinsic environment for sperm capacitation and fertilisation [13]. The wall of a goat's salpinx has tunica mucosa, tunica submucosa, tunica muscularis and tunica serosa layers from the lumen outwards $[13,19]$.

The fertility performance in small ruminants, which are seasonally polyestrous, is very important in economic terms. The knowledge of morphology and measurements of female genital organs will provide important information for artificial insemination, in vitro fertilisation and diagnosis of genital tract diseases. Studies exist for the organs of the female genital system in different breeds of goats and sheep $[10,12]$. However, a study of Anatolian wild goat (C. aegagrus aegagrus) was not found in the literature. This study will fill this knowledge gap in the literature.

This study aimed to investigate the anatomical and histological structure of the salpinx and ovary of Anatolian wild goat (C. aegagrus aegagrus).

\section{MATERIALS AND METHODS}

Permission was obtained from the Kafkas University Animal Experiments Local Ethics Committee (KAÜHADYEK), General Directorate of Nature Protection and National Parks of the Ministry of Agriculture and Forestry for this study (21264211-288.04/E.3790788). In this study, wild goats were used as material. These goats were brought to Kafkas University Wildlife Res-

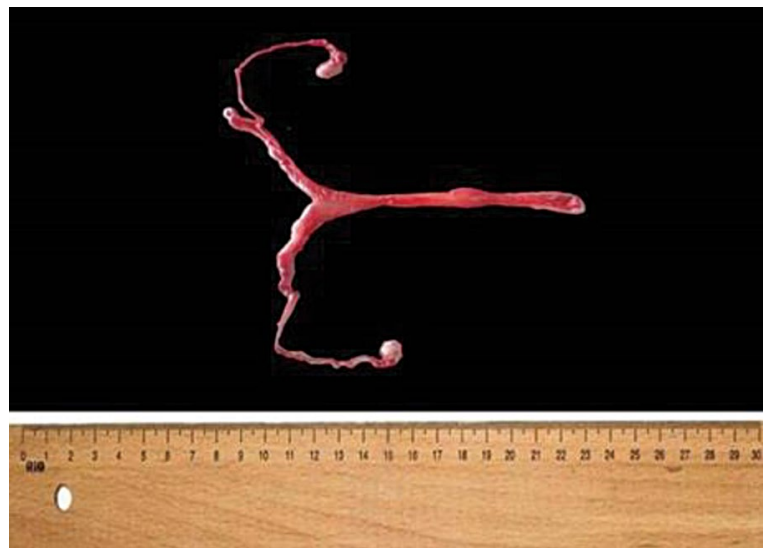

Figure 2. Study material and measurements taken.

cue and Rehabilitation Centre (Kars, Turkey) from many provinces of the Eastern Anatolia Region for various reasons such as traffic accidents and firearm injury, but could not be saved or needed to be euthanased according to the Wildlife Rescue and Rehabilitation Centre staff. The salpinx and ovaries of four wild goats of a similar age were dissected (Fig. 2). Measurements were taken from the right-left salpinx and ovary using digital callipers. The length of the salpinges was measured from the infundibulum tubae uterinae and pars uterina. The length of the ovaries was measured from the extremitas uterina and extremitas tubaria. The width of the ovary was measured between the margo mesovaricus and margo liber. The thickness of the ovaries was measured between the facies medialis and facies lateralis. The 


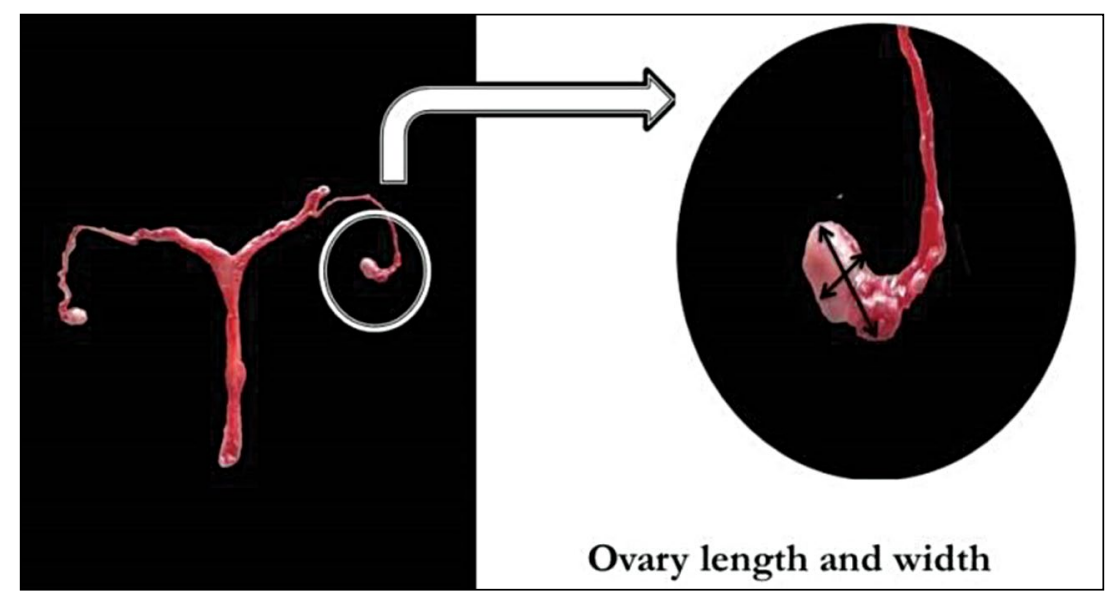

Figure 3. Ovarian measurements.

weight of each ovary and salpinx was measured using a precision scale (min: $0.0001 \mathrm{~g}$, max: $220 \mathrm{~g}$, code: XB220A, Precisa ${ }^{\circledR}$, Swiss). Lengths were recorded in $\mathrm{mm}$ and weights were recorded in grams. The histological structure of tissues and organs were examined after weighing. Salpinx tissue samples were fixed in $10 \%$ formalin solution, dehydrated through graded alcohol and cleared in xylene. Tissues were infiltrated and embedded in paraffin. Sections $(5 \mu \mathrm{m})$ from the paraffin blocks were stained with Crossman's triple stain and periodic acid Schiff (PAS). Sections were examined using light microscopy (Carl Zeiss Microscopy, Göttingen, Germany) and photographed.

\section{RESULTS}

\section{Anatomical results}

Anatolian wild goat ovaries were almond shaped in the sublumbar region and apertura pelvis cranialis. The mean weight of the ovary was $0.59 \pm 0.17 \mathrm{~g}$, length was $13.22 \pm 1.27 \mathrm{~mm}$, width was $8.46 \pm$ $\pm 0.88 \mathrm{~mm}$ and thickness was $5.67 \pm 0.79 \mathrm{~mm}$ (Fig. 3). Two of the goats had a longer left ovary. The length of the right ovary was $13.10 \pm 1.48 \mathrm{~mm}$ and the left ovary was $13.33 \pm 1.09 \mathrm{~mm}$. The width of the right ovary was $8.99 \pm 1.07 \mathrm{~mm}$ and the left ovary was $7.98 \pm$ $\pm 1.04 \mathrm{~mm}$. The thickness of the right ovary was $5.99 \pm 0.82 \mathrm{~mm}$ and the left ovary was $5.35 \pm$ $\pm 0.86 \mathrm{~mm}$. The weight of the right ovary was $0.66 \pm$ $\pm 0.16 \mathrm{~g}$ and the left ovary was $0.52 \pm 0.20 \mathrm{~g}$ (Table 1 ).

The salpinx was more convoluted than other goats salpinx in structure and shorter in length. The average length of the salpinx was $58.11 \pm 14.02 \mathrm{~mm}$, width was $0.80 \pm 0.22 \mathrm{~mm}$, thickness was $0.41 \pm 0.01 \mathrm{~mm}$, and weight was $0.30 \pm 0.08 \mathrm{~g}$. Salpinx length
Table 1. Selected wild goat ovarian measurements

\begin{tabular}{lccc}
\hline \multirow{2}{*}{ Measurement } & \multicolumn{2}{c}{ Wild goat } & \multirow{2}{*}{ Mean } \\
\cline { 2 - 3 } & Right & Left & \\
\hline Ovary's length [mm] & 13.10 & 13.33 & 13.21 \\
Ovary's width [mm] & 8.99 & 7.98 & 8.48 \\
Ovary's thickness [mm] & 5.98 & 5.35 & 5.66 \\
Ovary's weight [g] & 0.66 & 0.52 & 0.59 \\
\hline
\end{tabular}

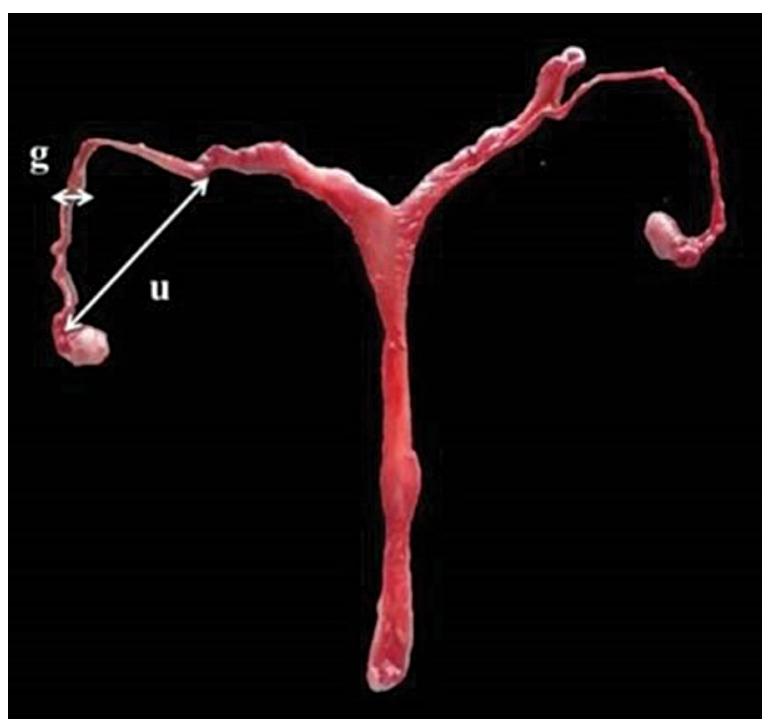

Figure 4. Salpinx measurement; $g$ - salpinx width; $u$ - salpinx length.

was $59.38 \pm 16.06 \mathrm{~mm}$ on the right side and $56.87 \pm 12.51 \mathrm{~mm}$ on the left side (Fig. 4). Salpinx width was $0.86 \pm 0.21 \mathrm{~mm}$ on the right side and $0.73 \pm 0.23 \mathrm{~mm}$ on the left side. Salpinx weight was 
Table 2. Selected wild goat salpinx measurements

\begin{tabular}{lccc}
\hline Measurement & \multicolumn{2}{c}{ Wild goat } & Mean \\
\cline { 2 - 3 } & Right & Left & \\
\hline Salpinx's length [mm] & 59.38 & 56.87 & 58.12 \\
Salpinx's width [mm] & 0.86 & 0.73 & 0,79 \\
Salpinx's weight [g] & 0.31 & 0.3 & 0.3 \\
\hline
\end{tabular}

$0.31 \pm 0.07 \mathrm{~g}$ on the right side and $0.30 \pm 0.09 \mathrm{~g}$ on the left side (Table 2).

\section{Histological results}

We observed three regions (infundibulum, ampulla and isthmus) in the wall of the Anatolian wild goat's salpinx based on lumen width and mucosa thickness (Fig. 5). In addition, each of the three regions had tunica mucosa, tunica muscularis and tunica serosa. The tunica mucosa was further subdivided into lamina epithelialis and lamina propria. Every part of the salpinx's mucosa had folds. The ampulla had the highest fold number and height of the three regions (Fig. 5B). The epithelium consisted of ciliated and non-ciliated prismatic cells. The infundibulum had the largest number of ciliated cells (Fig. 5A). We observed the tunica muscularis in the infundibulum, ampulla and isthmus formed two layers of circularly and longitudinally arranged smooth muscle fibres. The isthmus had the thickest smooth muscle and the narrowest lumen (Fig. 5C). The tunica serosa was comprised of mainly loose connective tissue, although vessels were also observed. The tunica serosa was thickest in the isthmus. Strong PAS staining in the infundibulum (Fig. 6A), ampulla (Fig. 6B) and isthmus (Fig. 6C) was observed.
When comparing regions, the infundibulum had the largest number of cells with PAS staining.

\section{DISCUSSION}

Some authors report ovaries in sheep and goats are almond shaped [1, 17], whereas others report they are flattened spheres [5]. In our study, the ovaries were almond shaped in the apertura pelvis cranialis in the sublumbar region in Anatolian wild goat. The mean ovary length is 10-20 $\mathrm{mm}[1,5,17]$ in small ruminants, but it was $13.22 \pm 1.27 \mathrm{~mm}$ in Anatolian wild goat. In our study, the right and left ovary lengths of the wild goat were $13.10 \pm 1.48 \mathrm{~mm}$ and $13.33 \pm$ $\pm 1.09 \mathrm{~mm}$, respectively. In Bengal goats, the right ovary mean length was $12.6 \pm 0.4 \mathrm{~mm}$ and the left ovary was $12.8 \pm 0.2 \mathrm{~mm}[10]$. However, in a different study of the same animal, the right ovary length was $14.53 \pm 0.34 \mathrm{~mm}$ and the left ovary length was $14.10 \pm 0.26$ [8]. The right ovary width in Bengal goats was $9.4 \pm 0.2 \mathrm{~mm}$ and the left ovary width was $9.0 \pm 0.3 \mathrm{~mm}[10]$. In this study, the right and left ovary width of the wild goats was $8.99 \pm 1.07 \mathrm{~mm}$ and $7.98 \pm 1.04 \mathrm{~mm}$, respectively. The ovary lengths obtained are in the range of data reported for domestic ruminants. The shortness of the ovary width in wild goats compared to Bengal goats could be based on age, weight, and race differences of the animals used in the study.

Ovary weight in small ruminants varies between 1.8 and $3.5 \mathrm{~g}[1,5,17]$ and in various studies. In this study, the wild goats' mean ovary weight was $0.59 \pm$ $\pm 0.17 \mathrm{~g}$. The right ovary weight was $0.53 \pm 0.02 \mathrm{~g}$ and left ovary weight was $0.52 \pm 0.02 \mathrm{~g}[10] \mathrm{in}$ a black Bengal goat study, whereas the right ovary
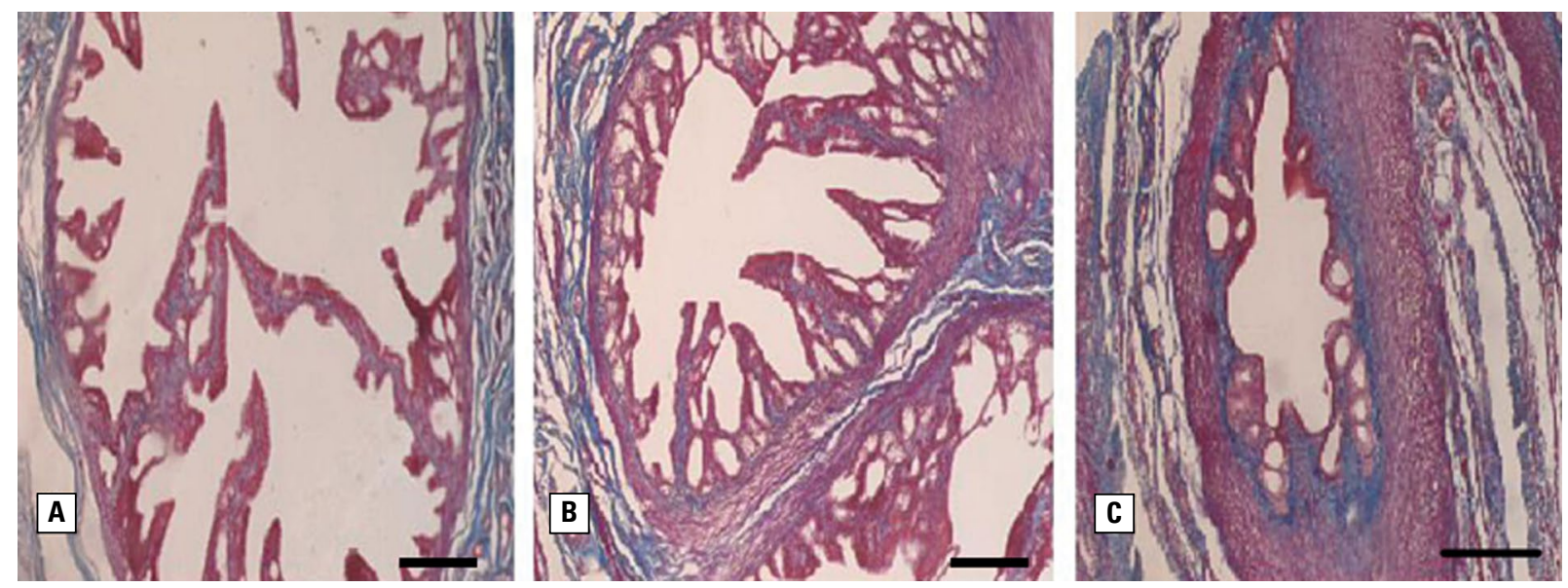

Figure 5. Anatolian wild goat's salpinx; A. Infundibulum, B. Ampulla, C. Isthmus. Triple staining, bar: $200 \mu \mathrm{m}$. 

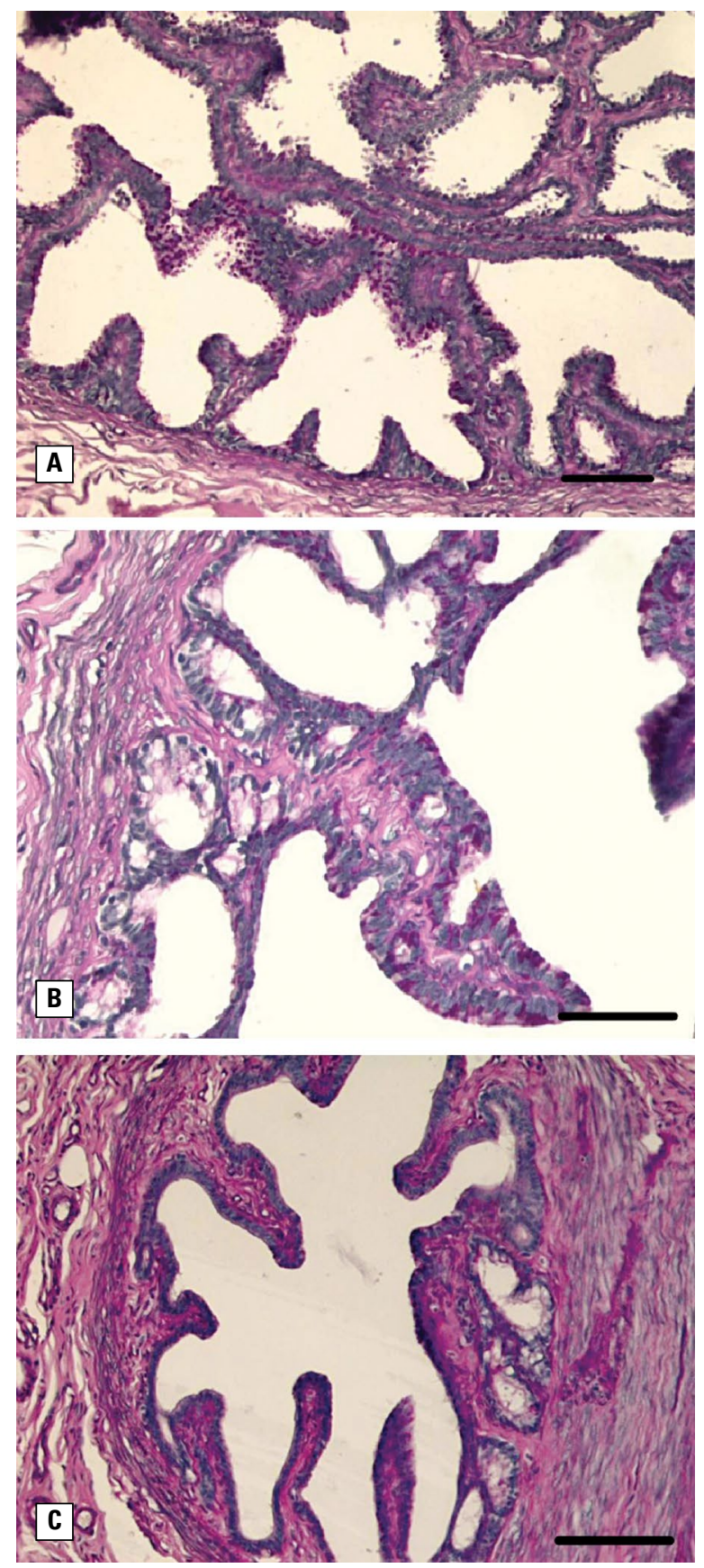

Figure 6. Anatolian wild goat's salpinx. PAS staining, bar: $100 \mu \mathrm{m}$. A. Infundibulum; B. Ampulla; C. Isthmus.

weight was $0.61 \pm 0.07 \mathrm{~g}$ and left ovary weight was $0.59 \pm 0.06 \mathrm{~g}[8]$ in another study. Here, the right and left ovary weights were $0.66 \pm 0.16 \mathrm{~g}$ and $0.52 \pm 0.20 \mathrm{~g}$, respectively. Based on these studies, the right ovary is heavier.

Puranik and Kaikini [15] measured the length of the right and left salpinx as $175 \mathrm{~mm}$ and $190 \mathrm{~mm}$, whereas Shalini [18] measured them as $109 \mathrm{~mm}$ and $205 \mathrm{~mm}$, respectively, in goats. Salpinx length is 150-160 mm [5] in sheep and goats and $101.50 \pm$ $\pm 2.28 \mathrm{~mm}[8]$ in Bengal goats, whereas it was $58.11 \pm 14.02 \mathrm{~mm}$ in Anatolian wild goat. Compared to domestic goats, wild goat has a shorter salpinx.

The ovary is divided into two functional parts, the cortex and medulla. The germinal epithelium on the surface of the ovary cortex was covered with simple cubic cells. The capsule was covered with thick, irregular connective tissue under the surface epithelium. Primordial, primary, secondary, and Graafian follicles were in various stages of development in the tunica albuginea. The medulla has a large vessel and neural network with frequent, irregular connective tissue [9].

The salpinx of goat, sheep and other domestic animals consists of the tunica mucosa, tunica submucosa, tunica muscularis and tunica serosa layered from the lumen outwards. In addition, the tunica mucosa consists of lamina epithelialis and lamina propria. Lamina propria and tunica submucosa are blended together because of the absence of distinct lamina muscularis and submucosa $[6,12,19,20]$. We observed that the wall of Anatolian wild goat's salpinx had tunica mucosa, tunica muscularis, and tunica serosa. In addition, the tunica mucosa consisted of lamina epithelialis and lamina propria, similar to the above studies. Natarajan et al. [14] reported the salpinx consisted of three regions (infundibulum, ampulla and isthmus) throughout the length of the salpinx. In addition, the ampulla had the most mucosal folds among the three regions. Bacha and Bacha [4] noted that in the infundibulum of a cow, the mucosa was highly folded whereas the muscularis was relatively thick. In the isthmus, they noted that the mucosa had fewer folds than any other part of the salpinx. Saleem et al. [16] reported all three regions contained both secretory and ciliated cells in tubal parts. Joshi et al. [12] conducted a histomorphological study of fallopian tube mucosa in ageing goat. They reported pseudostratified secretory cells over the surface of the tubal epithelium. In the isthmus, they found the mucosa was lined chiefly by non-ciliated cells in the infundibulum, whereas the non-secretory ciliated cells increased caudally. Towards the isthmus, the epithelium decreased in height and gradually changed to a non-secretory simple columnar ciliated type. Our investigation corresponded closely with Saleem et al. [16]; we also observed the infundibulum had the most ciliated cells. 
Dellmann and Eurell [6] stated that the tunica muscularis consisted chiefly of circular smooth muscle bundles. In the infundibulum and ampulla, the tunica muscularis was thin and composed of an inner circular layer and a few outer longitudinal bundles of smooth muscle. In the isthmus, the inner muscle layers were prominent. Tunica serosa contained many blood vessels and nerves. Bacha and Bacha [4] noted the tunica muscularis was the thickest in the isthmus formed by circular smooth muscle with longitudinally arranged external smooth muscle. This is in agreement with the findings of earlier studies. Histochemical studies show a strong PAS positive reaction in the apical epithelium of the infundibulum, ampulla and isthmus $[13,14]$. Similarly, we saw a PAS reaction in the apical epithelium of the infundibulum, ampulla and isthmus in our study.

\section{CONCLUSIONS}

The Anatolian wild goat is part of the wildlife diversity in Turkey, but the population has been decimated due to illegal and uncontrolled hunting and traffic accidents. We anatomically and histologically examined the salpinx and ovary of the genital system organs of this species. We believe this will support other studies seeking to increase reproductive efficiency and eliminate the extinction risk.

\section{Acknowledgements}

We would like to thank veterinarians Gizem Yaylagülü Büyükbaki and Burak Büyükbaki for their help at the Kafkas University Wildlife Rescue and Rehabilitation Centre (Kars, Turkey).

\section{REFERENCES}

1. Alaçam E. Obstetrics and infertility in domestic animals. 5th ed. Medisan, Ankara, Turkey 2005: 5-10.

2. Anonymous: Wild goat. https://tr.wikipedia.org/wiki/ Da\%C4\%9F ke\%C3\%A7isi (20.04.2018).

3. Anonymous: Wildgoat/Capraaegagru. http://www.tramem.org/memeliler/?fsx=2fsdl17@d\&tur=Yabanke\%C 3\%A7isi (25.04.2018).
4. Bacha WJ, Bacha LM. Color atlas of veterinary histology. Lippincott Williams \& Wilkins, United States of America 2000.

5. Bahadır A, Yıldız H. Veterinary Anatomy (Locomotor system and nternal organs). Revised 5th ed. Ezgi bookstore, 2014 : 325-328.

6. Dellmann HT. Eurell. In: Textbook of Veterinary Histology. 5th ed. Williams and Wilkins, Baltimore 1998.

7. Ellington JE. The bovine oviduct and its role in reproduction: a review of the literature. Cornell Vet. 1991; 81(3): 313-328, indexed in Pubmed: 1879144.

8. Gupta MD, Akter MM, Das A. Biometry of female genital organs of black bengal goat. Int J Nat Sci Res. 1970; 1(1): 12-16, doi: 10.3329/ijns.v1i1.8609.

9. Haque Z, Haque A. Abul Quasem MD. Gross and histomorphology of the ovary of Black Bengal Goat (Capra hircus). MJVR. 2015; 7(1): 37-42.

10. Haque Z, Haque A, Quasem M. Morphologic and morphometric analysis of the ovary of black bengal goat (capra hircus). Int J Morphol. 2016; 34(1): 13-16, doi: 10.4067/ s0717-95022016000100002.

11. Hunter RH. The fallopian tube: their role in fertility and infertility. Springer-Verlag, New York, USA 1988: 30-52.

12. Joshi CL, Nanda BS, Saigal RP. Histomorphological and histochemical studies on fallopian tube of ageing goat. Ann Anat. 1977; 141: 163-173.

13. Katare B, Singh G, Kumar $P$, et al. Histomorphological studies on the oviduct of goat (Capra hircus) during follicular and luteal phases. Haryana Vet. 2015; 54(1): 36-38.

14. Natarajan T, Prasad RV, Karade K, et al. Histological and histochemical studies on the oviduct of the buffalo (Bubalus bubalis) at different reproductive stages. Indian J Anim Sci. 2003; 73(5): 484-487.

15. Puranik JK, Kaikini AS. Biometry of genitalia of goats (Capra hircus L. ) Nagpur Vet Col Mag. 1968; 4: 39-44.

16. Saleem R, Suri S, Sarma K, et al. Histology and Histochemistry of Oviduct of Adult Bakerwali Goat in Different Phases of Estrus Cycle. J Anim Res. 2016; 6(5): 897, doi: 10.5958/2277-940x.2016.00116.9.

17. Semacan A, Kaymaz M, Fındık M, et al. Obstetrics and gynecology in farm animals. Medipres Matbaacllık, Malatya, Turkey. 2012: 525-530.

18. Shalini S. Anatomical studies on the female genital system of Gaddi goat. Masters Dissertation, Himachal Pradesh Krishi Vishvavidyalaya. Palampur. 1997: 24-30.

19. Singh GK, Prakash P. Effect of age on the morphological changes in the uterus of goat. Indian J Anim Sci. 1990; 55: 426-428.

20. Singh RA, Madan ML. Histological observations on reproductive organs in response to hormone administration in cyclic ewes. Indian J Anim Sci. 1989; 59: 250-257. 